\title{
Providing a statewide citation/ location service in New Jersey
}

\author{
By Margie Epple \\ Coordinator for Circulation and \\ Interlibrary Services \\ Rutgers University Libraries
}

\author{
and Carol Paszamant \\ Citation/Location Center Librarian \\ Rutgers University Libraries
}

\section{Rutgers provides a full range of document delivery services to members of the New Jersey Library Network.}

\section{$\mathbf{L}$}

ibraries of all types in New Jersey now have a place to turn when local library resources are inadequate to meet the informational needs of their patrons. Through a contractual agreement with the New Jersey State Library, a Citation/ Location Center (C/L Center) was established in 1988 within the Alexander Library-the Rutgers University Libraries, social sciences and humanities research library - to provide citation verification and location information to the over 1,800 member libraries of the New Jersey Library Network. With the addition of this new service, New Jersey Library Network members now have access to "total" document delivery services-whether the item is locatable in the RLIN or OCLC database or through other more specialized document delivery services.

\section{The New Jersey library network and statewide services}

The New Jersey Library Network was established in 1986 with the purpose of improving access to library materials and information for the residents of New Jersey. At that time, six multitype library cooperatives were established to coordinate delivery of network services on a regional basis, and a program of statewide services was established to offer network members access to unique library resources on a statewide basis.

Seven State Contract Libraries provide supplemental reference support and interlibrary loan services to Network member libraries. The Princeton University Library, New Jersey Institute of Technology, Newark Public Library, New Jersey State Library, Stevens Institute of Technology, the University of Medicine and Dentistry of New Jersey and the Rutgers University Libraries loan materials to New Jersey Library Network members and/ or handle reference inquiries in specified subject areas.

In addition to these regional and statewide services, two other new services were introduced to improve access to interlibrary services for all network members: the New Jersey OCLC Access Center and the Citation/Location Center at Rutgers University.

In September 1985 the New Jersey OCLC Access Center began operation. Through the Access Center, non-OCLC member network libraries were provided access to the OCLC database and interlibrary loan subsystem. By calling a toll-free telephone number, libraries throughout the state may request photocopies of journal articles and/or book loans. While the caller is on the telephone, Access Center staff search and place interlibrary loan requests, with materials sent directly to the borrowing library. It is the borrowing library's re- 
sponsibility to inform the Access Center when items are received from or returned to the lending library so that the Center may update the OCLC transaction record. The borrowing library also absorbs all charges and costs associated with borrowing.

The Access Center is heavily used by the New Jersey Library Network members. During the first month of operation in 1985, fifty-seven interlibrary loan requests were initiated by the Access Center on behalf of member libraries. By 1989 , between 5,000 and 6,000 requests were initiated each month.

As Access Center use grew, it became evident that a certain number of Access Center requests could not be filled either because of inaccurate citations or the lack of locations in the OCLC database. Similarly, OCLC libraries in the State often sought materials that could not be located in the database. To meet this need beyond OCLC the Citation/Location Center was established at Rutgers University.

Before the Citation/Location Center was established, most New Jersey librarians had no recourse beyond OCLC. Now, if the citation cannot be verified or the materials located on OCLC, the Access Center staff refers the librarian to the Citation/Location Center. Likewise, when librarians in OCLC member libraries cannot verify or locate materials via OCLC, they too can call the Center.

\section{The Citation/Location Center}

When the Citation/Location Center opened in October 1988, libraries from throughout New Jersey began to call the Center librarian for higher level searching and the verification of questionable citations. The Center now acts as the agency of last resort, verifying bibliographic data for incomplete or inaccurate citations, identifying locations from which specific items may be obtained, and placing third party ILL requests on behalf of the originating library or obtaining documents from commercial document delivery services.

\section{Staff and Center organization}

The Center is a separately staffed, state-funded department within the Rutgers University Libraries. It is currently staffed by one librarian who has direct access to the RLIN and OCLC databases and dial-up access to other online databases such as Dialog.

A toll-free 800 line was installed to receive incoming calls. As with the Access Center, the $\mathrm{C} / \mathrm{L}$ Center is reached most frequently via the toll-free telephone line, but requests may also be sent by telefacsimile machine. Librarians may call any time during the hours 8:30 a.m. to 4:30 p.m. and may also leave requests on an answering machine connected to the toll-free line. In any case, Center staff will respond to the request within 48 hours of receipt (or two working days) by supplying the item from the University Libraries, collections, placing an ILL request on behalf of the requesting library through OCLC or RLIN, ordering the item through a commercial document delivery service such as NTIS, UMI Article Clearinghouse, Dialog, etc., or supplying an OCLC local library with the correct citation in order to initiate the request themselves.

All requests are responded to in detail either by telephone, delivery service, or telefacsimile. When an item cannot be found, the Center librarian will provide information on sources searched.

The Center has separate (from any of the Rutgers libraries) I.D.'s and symbols on RLIN (NJCG) and OCLC (NJZ) and is a borrower only on the two ILL subsystems. As with the Access Center, the borrowing library accepts responsibility for returning the material to the lending library and for notifying the Center to provide for updating of online records on OCLC or RLIN. Unlike the Access Center, however, all costs for borrowinglending fees, photocopy charges, document costs - are absorbed by the Citation/Location Center.

During the first six months of operation, the Center received 609 requests for verification of citations and/or location of materials, and the number of requests received per month continues to grow as the service becomes an integral part of Library Network services in New Jersey. During October 1988, the first month of operation, 36 requests were processed, while in March 1989 Center staff responded to 154 inquiries, an increase of over 400 percent.

\section{Center clients}

The types of libraries contacting the Center for assistance run the full spectrum-academic, school, public, special, and institutional. When the Center was first conceived, Rutgers, staff involved in the planning for the Center had the notion that public and school libraries would dominate use of the Center, with moderate use anticipated by special libraries. They anticipated minimal use by academic libraries, which they thought would rely on their own collections. Time has confirmed some of these expectations, but not others.

Requests from public libraries have indeed averaged $43 \%$ of total usage, more than requests from any other type of library. However, requests from school libraries have not amounted to the numbers anticipated, averaging $10 \%$ of total requests over the first six months of the service. At the same time requests from special libraries have surpassed pro- 
jected figures and amount to $38 \%$ of total activity during the same time period. Academic libraries have initiated $9 \%$ of the requests handled by the Center. Center staff will continue to monitor originating library statistics to determine if these trends will continue over longer periods of time and what impact the requesting library type may or may not have on Center policies.

\section{Types of requests}

The requests range in difficulty from simple RLIN title searches and the placement of interlibrary loan requests to the in-depth searching of print and online sources. Staff have found unpublished conference proceedings by locating authors through parent organizations, have located printed sheet music by a 19 th-century composer by dealing directly with a German publisher, and have called institutes and associations to verify and obtain publications.

Although most of the libraries call in their requests via the 800 number, use of telefacsimile has been on the increase and has been especially helpful for long, multiple, or difficult to describe citations. Mail and delivery service have been employed to a lesser extent. Precise figures are not yet available, but most libraries want actual documents if possible, not just citation verification or location. In some instances, however, library staff seek only locations of known items that they have not been able to locate on OCLC through the Access Center or by directly searching OCLC themselves.

The many types of materials requested have included books, journal and newspaper articles, manuscripts (locations or microform editions), state and federal documents, conference proceedings, technical reports, music scores, essays, plays, and poems. While most material is in print format, microforms, kits, and audio and videocassettes (difficult to find and borrow) have also been sought.

In January 1989 the Center began keeping records of the general subject area of each request: humanities, social science, science/technology, or medicine. To date, requests have been distributed fairly evenly among the subject areas, with humanities requests slightly predominating.

Examples of three requests follow, along with actions taken to locate the materials.

A special library was looking for a paper from the 1985 Conference on Coal Gasification Systems and Synthetic Fuels for Power Generation (Proceedings) by the American Gas Association. A check of the Rutgers' online and card catalogs was negative.

The two entries for the American Gas Association in the New Jersey Union List of Serials and Rutgers Union List of Serials had been discontinued prior to 1985 and did not have the conference title either. RLIN and OCLC searches were also negative. In the British Lending Library's Index of Conference Proceedings Received, the title appeared in the 1986 volume, but the sponsor shown was the Electric Power Research Institute (EPRI), rather than the American Gas Association. A call to EPRI led to a project manager who verified that the paper was in their proceedings. He sent a copy of the paper along with current updates directly to the requesting library at no charge.

A medical library requested an item from the National Rehabilitation Information Center (NRIC) database. The citation provided appeared complete with the author, title, year, number of pages, and corporate sponsor but could not be located by the Access Center. Searches of RLIN and OCLC yielded no record. The report was located in Government Reports Announcements and Index, and, with the report number obtained, the item was ordered from NTIS.

A public library patron wanted printed sheet music, a particular piece by a 19th-century composer, Julian Fontana. The composer's existence had been verified in Grove's Dictionary of Music and Musicians, but neither he nor the piece title were in the OCLC or RLIN database. The Laurie Music Library at Rutgers was able to find the composer and piece listed in an index which gave the publisher but no other information. Upon calling the American distributor for the German publisher, the Center was informed that the work was no longer in print, but that archival copies could be made. This information, together with copy costs, were supplied to the patron via the requesting library.

\section{Processing of requests}

Statistics are kept on the number and type of requests received and are reported to the State Library on a monthly basis. In analyzing the disposition of requests, items sought are considered to be either located (with or without placement of an ILL request), not located, misdirected/canceled, or still pending a final outcome at the time of evaluation. The "not located" category includes documents which have not yet been published, as corroborated by the publisher, as well as those which cannot be verified or located. The Center has obtained some unpublished material directly from authors, and has considered these items "located." When a librarian merely seeks additional locations for a known item, the Center considers the item located only if at least one new location is discovered.

The Center has located between $70 \%$ and $82 \%$ of requested materials each month, excluding misdirected and canceled requests. Misdirected requests-those for which the Center does not as- 
sume jurisdiction-comprise reference questions, general subject searches, and situations in which an appropriate OCLC search had not been conducted by the Access Center or a regional contract library. When feasible, Center staff does attempt to answer misdirected requests. Over the six-month period, misdirected and canceled requests have ranged between $5 \%$ and $7 \%$ of the total. No more than two requests have remained unresolved beyond the report time for any one month.

The program guidelines call for a reply, whether final or interim, to be provided for $85 \%$ of requests within two working days from the date of initiation. To date, response time has averaged about one work day, with between $84 \%$ and $99 \%$ of requests receiving a reply within two working days.

The requests range from the general to the highly technical. The more technical requests usually originate in the academic and special libraries but may also come from public library sources. The amount of information initially provided by the requesting libraries varies from a complete citation to only a title, and the information that is provided is often incorrect. One patron of a public library could not remember if the book he wished to reread after 20 years had been in English or Hungarian, and remembered only the subject and one word from the title (the Center was unable to locate this item).

\section{Current issues and the future}

So far, the number of requests has remained at under 500 requests per quarter as projected in the original agreement with the State Library. With 419 requests processed in the second quarter of operation, however, it seems quite possible that demand will exceed the 2,000 request level projected for 1989. If the service can be maintained or even improved, traffic will most likely continue to increase as more Network member libraries be- come aware of and familiar with the Center's services, and as interlibrary loan transaction levels increase in the state. Patron requests which had been abandoned for months can now be directed to one last resource; indeed, many of the requests the Center receives are quite old.

Certain policies still need to be refined, as recurring issues demonstrate. One such issue has been the exact demarcation between the Access Center and the Citation/Location Center services. Since both have OCLC, member libraries become understandably confused about which one has entered an ILL request on their behalf, and which one to call if only partial information is available, as the Access Center can often locate an item using partial information.

The line between interlibrary loan and reference service represents another recurring issue - many times the boundary between a reference request and a citation request is unclear. The Citation Location Center is funded to provide sophisticated document delivery services and is limited in its ability to provide in-depth reference searching. From the number and types of questions in the "misdirected" statistical category each month, it is obvious that it is often difficult to distinguish between reference and citation queries on a local library level.

A third issue has been when the Center should assume document delivery costs, and when the requesting library should. The contract calls for the Center to cover these costs; however, in order to stay within its budget, staff must exercise discretion and avoid abuse by a library which needs many documents available only from commercial sources or seeks to augment its collection at the Center's expense.

As issues emerge, so will resolutions. In the meantime, present and future trends seem to indicate that reliance on the Center is sure to continue and grow.

\section{Labor records saved}

The University at Albany, State University of New York, has announced that it is preserving the records of the Hudson Valley Area Joint Board of the Amalgamated Clothing and Textile Workers Union through a generous New York State grant in support of the ongoing Harry Van Arsdale Jr., Labor History Project. These are the first records saved through the project.

Dating from the 1930s to the 1980 s, the more than 30 boxes of historical records include minutes of meetings, contract negotiations, arbitrations, scrapbooks, photographs, and memorabilia. Also included are records of labor councils and joint boards from Newburgh to Troy. The records were selected from hundreds of boxes of records stored at the Hudson Valley Area Joint Board's offices in Hudson, New York, with the help of Robert L. Redlo, manager of the Joint Board and vice-president of the Upper Hudson Valley Labor Council.

As part of the project, the University is surveying hundreds of labor organizations in the Capital District. For more information contact Geoffrey Huth, Field Archivist, University Libraries, B-49, University at Albany, State University of New York, 1400 Washington Avenue, Albany, NY 12222; (518) 442-3541. 